\title{
BMJ Open Which anthropometric measures best indicate type 2 diabetes among Russian, Somali and Kurdish origin migrants in Finland? A cross-sectional study
}

\author{
Natalia Skogberg, ${ }^{1,2}$ Tiina Laatikainen, ${ }^{3,4,5}$ Annamari Lundqvist, ${ }^{3}$ Eero Lilja, ${ }^{2}$ \\ Tommi Härkänen, ${ }^{3}$ Päivikki Koponen ${ }^{3}$
}

To cite: Skogberg N, Laatikainen T, Lundqvist A, et al. Which anthropometric measures best indicate type 2 diabetes among Russian, Somali and Kurdish origin migrants in Finland? A crosssectional study. BMJ Open 2018;8:e019166. doi:10.1136/ bmjopen-2017-019166

- Prepublication history and additional material for this paper are available online. To view these files, please visit the journal online (http://dx.doi org/10.1136/bmjopen-2017019166).

Received 15 August 2017 Revised 23 February 2018 Accepted 10 April 2018

\section{Check for updates}

${ }^{1}$ Department of Public Health, University of Helsinki, Helsinki, Finland

${ }^{2}$ Department of Welfare, National Institute for Health and Welfare, Helsinki, Finland

${ }^{3}$ Department of Public Health Solutions, National Institute for Health and Welfare, Helsinki,

Finland

${ }^{4}$ Institute of Public Health and Clinical Nutrition, University of Eastern Finland, Kuopio, Finland ${ }^{5}$ Joint Municipal Authority for North Karelia Social and Health Services, Joensuu, Finland

Correspondence to Natalia Skogberg; natalia.skogberg@thl.fi

\section{ABSTRACT}

Objectives To compare the performance of body mass index (BMI), waist-to-height ratio (WHtR), waist circumference (WC) and waist-to-hip ratio (WHR) in detecting type 2 diabetes among Russian, Somali and Kurdish (born in Iraq//ran) origin migrants and Finns.

Design and participants Cross-sectional study comparing health examination survey data of Russian, Somali and Kurdish origin migrants $(\mathrm{n}=917)$ aged $30-64$ years who took part in the Migrant Health and Wellbeing Survey with the general Finnish population in the Health 2011 Survey $(n=887)$. Participants were randomly selected from the National Population Register.

Setting Six cities in Finland, where a substantial majority of migrants live.

Outcome measures Anthropometric measures included objectively measured BMI, WHtR, WC and WHR. Type 2 diabetes was defined based on self-report, laboratory measures of glycated haemoglobin and register data. Test performance was assessed using receiver operating characteristics curves, using area under the curve (AUC) as a measure of accuracy.

Results Among Finns, test performance was highest for WC (AUC $=0.81,95 \% \mathrm{Cl} 0.74$ to 0.87 ) and WHtR ( $\mathrm{AUC}=0.81,95 \% \mathrm{Cl} 0.75$ to 0.87 ). Test performance was similar for BMI (AUC $=0.80,95 \% \mathrm{Cl} 0.67$ to 0.92), WC (AUC $=0.79,95 \% \mathrm{Cl} 0.67$ to 0.91$)$ and WHtR ( $\mathrm{AUC}=0.70$, $95 \% \mathrm{Cl} 0.66$ to 0.93 ) among Russians. WC and WHtR had highest test performance also among Somali (AUC $=0.74$, $95 \% \mathrm{Cl} 0.64$ to 0.84 for $\mathrm{WC}$ and $\mathrm{AUC}=0.75,95 \% \mathrm{Cl} 0.65$ to 0.85 for WHtR) and Kurds (AUC $=0.71,95 \% \mathrm{Cl} 0.61$ to 0.81 for WC and $A U C=0.70,95 \% \mathrm{Cl} 0.59$ to 0.80 for WHtR). Among migrants, WHR had the poorest test performance. Conclusion WC and WHtR performed overall the best across all study groups, however, accuracy of detection was lower particularly among Somali and Kurds. Currently used diabetes risk assessment tools assume a strong association between anthropometrics and diabetes. These tools need to be validated among non-Western populations.

\section{INTRODUCTION}

Non-Western origin migrants have a higher prevalence of glucose impairment and type 2 diabetes, both compared with

\section{Strengths and limitations of this study}

- To our best knowledge, no previous studies have aimed at determining the best anthropometric measures for detecting type 2 diabetes among migrants of Eastern-European, African and Middle Eastern origin.

- A substantial strength of the study is use of randomised study design and inclusion of several diverse migrant groups.

- A further strength is the use of several objective standardised anthropometric measures and supplementation of self-report data with register-based data and laboratory analyses.

- Use of anthropometric measures as continuous variables takes into account the lack of specific cut-offs for Middle Eastern and African origin populations.

- One limitation could be the cross-sectional nature of the data, due to which we were unable to test causality by using follow-up data on diabetes diagnosis.

Europeans and compatriots in their country of origin. ${ }^{1-5}$ Prevalence of type 2 diabetes has been reported to be 2-5 times higher among South Asian, 2-4 times higher among Middle Eastern and North-African, and 2-3 times higher among Sub-Saharan African origin populations compared with Europeans. ${ }^{6}$ Non-Western origin migrants in Finland (Somali and Iranian/Iraqi Kurds) have also been reported to have a 3-5 times higher risk for glucose impairment and 2-3 times higher risk for diabetes compared with Finns. ${ }^{7}$ There is therefore an urgent need for effective screening strategies to identify those at elevated risk for type 2 diabetes.

Weight gain, particularly abdominal obesity, is strongly associated with insulin resistance, which is a central precursor for diabetes. ${ }^{89}$ Body mass index (BMI) and waist circumference (WC) are the most commonly used anthropometric measures for identifying populations at a higher risk for type 2 
diabetes. ${ }^{10}$ While BMI is an indicator of total body fat, it does not provide information on body fat distribution. WC reflects central fat deposition but does not take fully into account intraindividual and ethnic differences in lean body mass, body shape and height. ${ }^{11}{ }^{12}$ Body fat distribution, body shape and height may vary substantially according to country of origin, therefore, anthropometric measures that are more sensitive to these variations across population groups may need to be considered. ${ }^{11}$ Alternatives to BMI and WC include waist-to-hip ratio (WHR) and waist-to-height ratio (WHtR). While WHR reflects relative fat distribution, it is rather an indicator of body shape than of excess fat. ${ }^{12}$ Recently, WHtR was shown to be superior to BMI and WC in predicting future risk for type 2 diabetes by taking into account both central fat deposition and intraindividual differences in height. ${ }^{113}$

In addition to the apparent need for considering more appropriate anthropometric measures for non-Western origin migrants, currently used classifications of obesity may need to be reconsidered. Generally, the association between obesity and glucose impairment is examined using cut-off points that have been established based on large-scale studies conducted among Caucasian populations. ${ }^{12}$ Recent studies have demonstrated a weaker association between obesity and type 2 diabetes among migrants of South Asian, ${ }^{2}$ Middle Eastern ${ }^{3}$ and West African ${ }^{14}$ origin, which may be attributable to different mechanisms for developing type 2 diabetes. However, these findings may also be related to inappropriateness of current obesity classifications for non-Western origin migrants. There is increasing evidence that migrant populations have an increased risk of developing type 2 diabetes at lower BMI and WC levels than Western populations. ${ }^{15-17}$ Considering that diabetes risk prediction tools assume a strong association between obesity and type 2 diabetes, ${ }^{10}$ use of obesity cut-offs for Western populations may lead to misclassification of those at higher risk for diabetes among non-Western origin populations.

The aim of this study was to compare the performance of BMI, WHtR, WC and WHR in detecting type 2 diabetes among Russian, Somali and Kurdish (born in Iraq/Iran) origin migrants and the general Finnish population.

\section{METHODS}

\section{Design and study population}

This cross-sectional study was based on the data from the Migrant Health and Wellbeing Survey (Maamu), conducted between 2010 and 2012 in six cities in Finland. A more detailed description of survey methods has been provided elsewhere. ${ }^{7}$ Briefly, a stratified random sample of 3000 Russian, Somali and Kurdish origin migrants (1000 per each group) aged 18-64 years was drawn from the National Population Register that contains information on all permanent residents in Finland. Stratification was based on all combinations of the three migrant groups (Russian, Somali and Kurds) and the six cities where the study was conducted (Helsinki, Espoo, Vantaa, Turku,
Tampere and Vaasa). Somali migrants were not recruited in the city of Vaasa because at the point of planning the survey, the Somali population size was very low. Stratification was therefore based on altogether 17 combinations (Russian $\mathrm{x} 6$ cities $)+($ Somali $\mathrm{x} 5$ cities $)+($ Kurdish $\mathrm{x} 6$ cities $)$. A random sample was drawn in each stratum based on predetermined sample sizes. Inclusion criteria were country of birth (Russia/Former Soviet Union, Somalia and Iran/Iraq), mother tongue (Russian/Finnish and Sorani dialect of Kurdish) and residence in Finland for at least one year. Participants were invited for a structured face-to-face interview and a standardised health examination, conducted by trained fieldwork personnel.

The reference group were the general Finnish population (later referred to as Finns) who participated in the nationally representative Health 2011 Survey. ${ }^{18}$ The reference group consisted of participants from the corresponding six cities of the Maamu Survey. Survey data were supplemented with register-based data from the Social Institution of Finland (Kela) and the Finnish Care Register for Health Care (Hilmo). The Social Institution of Finland grants reimbursement rights for medication based on diagnosis and severity of the long-term condition. ${ }^{19}$ The Finnish Care Register for Health Care contains information on inpatient or outpatient hospital care. ${ }^{20}$

The current study was limited to health examination participants, aged 30-64 years, with participation rate of $48 \%$ for Russians, $40 \%$ for Somali, $59 \%$ for Kurds and $56 \%$ for Finns. Following exclusion of persons with type 1 diabetes $(n=9)$, the study was based on health examination data of 917 migrants and 887 Finns. All participants gave written informed consent.

\section{Clinical measurements and interview data}

The health examination included standardised measurements of weight and height as well as waist and hip circumferences according to the European Health Examination Survey standards. ${ }^{21}$ Weight was measured wearing light clothing and no shoes with a balanced beam scale (Seca 709) in the Maamu Survey and as a part of the bioimpedance body composition analysis (Seca 514) in the Health 2011 Survey. In both studies, height was measured without shoes with a stand-alone stadiometer (Seca 213). WC was measured with a soft measuring tape half-way between the lowest rib and top of iliac crest on bare skin or wearing light clothing. Hip circumference was not measured in the Health 2011 Survey and is available for Maamu Survey participants only. Weight and WC were not measured if the participant was over 20 weeks pregnant.

Blood samples were taken by trained laboratory staff, centrifuged within an hour and frozen at $-20^{\circ} \mathrm{C}$ on site. Samples were shipped packed in dry ice weekly in Helsinki, Espoo and Vantaa, and monthly in other cities, to their final storage location in THL, where they were stored at $-70^{\circ} \mathrm{C}$. Glycated haemoglobin (HbA1c) was measured by immunoturbidimetric method using Abbott Architect reagents. The interassay coefficient of variation 
for HbA1c was 3.9\%. The laboratory (Disease Risk Unit at THL) conducting the analyses took part in the External Quality Assessment Schemes organised by Labquality, Helsinki and Finland.

\section{Variable definition}

Variable

Type 2 diabetes was determined based on: (1) interview data on self-reported previous diagnosis by a physician, (2) self-reported medication use, (3) register-based diabetes defined by information on special medication reimbursement rights and/or inpatient or outpatient hospital care for diabetes and/or (4) HbA1c levels $\geq 6.5 \%$ (140 $\mathrm{mg} / \mathrm{dL})$. Diabetes type was not asked in the interviews, thus, persons with type 1 diabetes were identified as those who had diabetes onset below the age of 35 years and simultaneously used only insulin as their diabetes medication.

Anthropometric measures included in this study were BMI, WC, WHtR and WHR. BMI was calculated as $\mathrm{kg} /$ $\mathrm{m}^{2}$. WHtR was calculated as WC in $\mathrm{cm}$ divided by height in $\mathrm{cm}$. WHR was calculated as WC in $\mathrm{cm}$ divided by hip circumference in $\mathrm{cm}$. Age was used as a categorical variable ( $<45$ years vs $\geq 45$ years).

\section{Statistical analysis}

All analyses accounted for the stratified sampling and finite population correction and were conducted using the Sudaan V.11.0.1 and SAS V.9.3 software packages. ${ }^{22}$ Inverse probability weights, based on register information (age group, sex, study group, study location and marital status), were used to correct for the effects of non-response and different sampling probabilities in all of the analyses. $^{23}$ The regression analyses were based on the generalised estimating equations, and all variance estimates on linearisation. ${ }^{24}$

Age-adjusted mean values and their 95\% CIs for continuous variables were calculated using linear regression, whereas logistic regression was applied to categorical variables. All regression analyses were stratified by study group and sex, with exception for estimation of age-adjusted mean anthropometric measures according to the presence of type 2 diabetes. All regression analyses were conducted using predictive margins based on regression models. ${ }^{25}$ Statistical significance was assessed with Satterthwaite F-statistic. Logistic regression was applied to test the interaction between anthropometrics and sex with type 2 diabetes as an outcome variable for each study group. No statistically significant sex interactions were found for any of the continuous anthropometric variables in any of the study groups, therefore, mean anthropometric measures according to the presence of type 2 diabetes and area under the curve (AUC) were calculated jointly for men and women using the interaction of study group and sex.

Test performance of anthropometric measures was evaluated by receiver operating characteristics (ROC) analyses. $^{26}$ Accuracy of the test was assessed by calculating AUC. The perfect test has an AUC of 1.0, whether random chance gives an AUC of 0.5. The AUC values are classified as: $0.5-0.6$ fail, $0.6-0.7$ poor, $0.7-0.8$ fair, $0.8-0.9$ good and 0.9-1.0 excellent. ${ }^{27}$ Stratified sampling design based on the 17 combinations of migrant groups and study locations were accounted for when calculating the AUC values but not when calculating CIs for AUC and $\mathrm{p}$ values for the difference in the performance of anthropometric measures within each migrant group. The reason for not accounting for stratified sampling design in these analyses is that we are unaware of any accessible statistical tools for assessing the differences of AUC in complex survey data. ROC analyses were performed for each study group separately.

\section{RESULTS}

Age-adjusted anthropometric characteristics are presented in table 1 . Russian men were shorter, weighted less and had lower WC compared with Finns. Russian women were shorter, otherwise their anthropometric characteristics were similar to those of Finns. Somali men were shorter, weighted less and had lower WC compared with Finns. Somali women were also shorter but were simultaneously significantly heavier than Finns. Mean BMI and WHtR were significantly higher among Somali women compared with Finns, however, mean WC did not differ significantly between the two groups. Compared with Finns, Kurdish men were significantly shorter, weighted less and had lower WC, however, no statistically significant differences were observed with respect to BMI and WHtR. Kurdish women, on the other hand, were significantly shorter but had similar weight and WC as Finns, as reflected also in higher BMI and WHtR.

Prevalence of type 2diabetes as well as prevalence of each individual component (self-report, registers and HbA1c) that were combined to form a joint 'type 2 diabetes' variable are presented in table 2. Prevalence of type 2 diabetes was significantly higher among Somali and Kurds, particularly among women. Register-based prevalence of type 2 diabetes was higher than self-report among men in all study groups and Finnish women, whereas it was lower among Russian, Somali and Kurdish women. Prevalence of HbA1c $\geq 6.5 \%(140 \mathrm{mg} / \mathrm{dL})$ was higher among Somali and Kurdish men and Somali women compared with Finns.

Supplementing self-reported diabetes diagnosis with register-based data on special medication reimbursement rights for diabetes medicine and/or inpatient or outpatient hospital care/physician visits for diabetes treatment, provided with altogether 17 new cases of diabetes ( $n=7$ for Finns, $n=1$ for Russians, $n=4$ for Somali, $n=5$ for Kurds). Laboratory measures of HbAlc provided with an additional nine new cases of diabetes ( $n=2$ for Finns, $n=2$ for Russians, $n=5$ for Somali) in addition to the information based on self-report and registers.

Among persons with type 2 diabetes, mean age on arrival to Finland was 35 years for Russian, 32 years for Somali and 31 years for Kurds (detailed data not shown). 
Table 1 Age-adjusted anthropometric characteristics of the study population

\begin{tabular}{|c|c|c|c|c|}
\hline & \multirow{2}{*}{$\begin{array}{l}\text { Finnish } \\
\text { Mean }(95 \% \mathrm{Cl})\end{array}$} & \multirow{2}{*}{$\begin{array}{l}\text { Russian } \\
\text { Mean }(95 \% \mathrm{Cl})\end{array}$} & \multirow{2}{*}{$\begin{array}{l}\text { Somali } \\
\text { Mean }(95 \% \mathrm{Cl})\end{array}$} & \multirow{2}{*}{$\begin{array}{l}\text { Kurdish } \\
\text { Mean }(95 \% \mathrm{Cl})\end{array}$} \\
\hline & & & & \\
\hline Men, $N$ & 395 & 119 & 85 & 181 \\
\hline Weight, kg & 86.4 (84.5 to 88.3 ) & $82.9(80.1 \text { to } 85.7)^{\star}$ & $74.6(72.3 \text { to } 77.0)^{\star \star \star}$ & $80.9(79.3 \text { to } 82.5)^{\star \star \star}$ \\
\hline Height, cm & 179.6 (178.7 to 180.5$)$ & $176.6(175.4 \text { to } 177.7)^{\star \star \star}$ & $\begin{array}{l}174.5 \\
(173.0 \text { to } 176.0)^{\star \star \star}\end{array}$ & $171.6(170.7 \text { to } 172.4)^{\star \star \star}$ \\
\hline $\begin{array}{l}\text { Waist circumference, } \\
\mathrm{cm}\end{array}$ & 96.0 (94.5 to 97.5$)$ & $92.9(90.5 \text { to } 95.3)^{\star}$ & $87.1(85.1 \text { to } 89.1)^{\star \star \star}$ & $93.3(92.0 \text { to } 94.5)^{\star \star}$ \\
\hline $\begin{array}{l}\text { Body mass index, } \\
\mathrm{kg} / \mathrm{m}^{2}\end{array}$ & 26.7 (26.2 to 27.3 ) & 26.6 (25.8 to 27.4 ) & $24.5(23.8 \text { to } 25.3)^{\star \star \star}$ & 27.4 (26.9 to 27.9 ) \\
\hline Age $\geq 45$ years, $\%$ & 55.2 (50.2 to 60.1$)$ & 60.6 (53.6 to 67.2 ) & $35.3(27.6 \text { to } 43.7)^{\star \star \star}$ & $31.1(25.1 \text { to } 37.9)^{\star \star \star}$ \\
\hline Weight, kg & 72.2 (70.8 to 73.6$)$ & 71.5 (69.5 to 73.4$)$ & $80.9(78.4 \text { to } 83.3)^{\star \star \star}$ & $71.0(69.5$ to 72.6$)$ \\
\hline Height, cm & 165.9 (165.2 to 166.5$)$ & $164.0(163.1 \text { to } 164.8)^{\star \star \star}$ & $161.9(161.0 \text { to } 162.9)^{\star \star \star}$ & $157.4(156.7 \text { to } 158.2)^{\star \star \star}$ \\
\hline $\begin{array}{l}\text { Hip circumference, } \\
\text { cm }\end{array}$ & NA & 102.7 (101.2 to 104.2$)$ & 109.6 (107.8 to 111.4$)$ & 100.5 (99.2 to 101.8$)$ \\
\hline $\begin{array}{l}\text { Waist circumference, } \\
\mathrm{cm}\end{array}$ & 86.8 (85.4 to 88.1$)$ & 85.1 (83.3 to 86.9 ) & 88.3 (86.5 to 90.1$)$ & 88.5 (86.9 to 90.0$)$ \\
\hline $\begin{array}{l}\text { Body mass index, } \\
\mathrm{kg} / \mathrm{m}^{2}\end{array}$ & 26.3 (25.8 to 26.8 ) & 26.6 (25.8 to 27.3 ) & $30.8(29.9 \text { to } 31.6)^{\star \star \star}$ & $28.6(28.0 \text { to } 29.3)^{\star \star \star}$ \\
\hline
\end{tabular}

$P$ value is presented for the difference between each migrant group and Finns.

${ }^{*} \mathrm{P}<0.5,{ }^{* *} \mathrm{P}<0.001,{ }^{* * *} \mathrm{P}<0.001$.

$\mathrm{NA}$, not applicable.

Self-reported mean age at diagnosis was 48 years for Russians, 45 years for Somali, 41 years for Kurds and 45 years for Finns. The difference in age of diagnosis was statistically significant among Kurds $(p=0.006)$ and approached statistical significance for Russians $(\mathrm{p}=0.058)$ when comparing with Finns. Type 2 diabetes was diagnosed in Finland in majority of the cases (72\% among Russians, 59\% among Somali and $70.5 \%$ of Kurds).

Mean BMI values varied significantly among persons with and without type 2 diabetes in Finnish and Russian groups, whereas the difference was less pronounced among Somali and Kurds (table 3). Similar observations were made for WC, WHtR and WHR. Additionally, while mean BMI values were overall similar in corresponding diabetes categories across all groups, mean WC among Somali and Kurdish origin persons with type 2 diabetes was significantly lower compared with that of Russians and Finns. Somali origin migrants with type 2 diabetes had a significantly lower mean WHtR compared with Finns.

Results of the ROC curves are presented in table 4 and in figure 1. ROC curves showed that test performance was similar for $\mathrm{WC}$ and $\mathrm{WHtR}$ and significantly poorer for BMI among Finns. Accuracy of detection for WC and $\mathrm{WHtR}$ was good (AUC within the range of $0.80-0.90$ ) and fair for BMI (AUC within the range of 0.70-0.80). Among Russians, test performance was similar for BMI, WC and WHtR (AUC ranging between 0.79 and 0.80 ), with fair to good accuracy of detection. For Somali, test performance was similar for WC and WHtR and poorer for BMI. Accuracy of detection for WC and WHtR was fair among the Somali group (AUC within the range of $0.70-0.80$ ) and poor for BMI (AUC within the range of $0.60-0.70$ ). As in all other groups, test performance was similar for WC and WHtR among Kurds as well. However, accuracy of detection ranged between AUC 0.70 and 0.71 , suggesting poor to fair test performance.

WHR (available for migrants only) performed the poorest across the examined anthropometric measures across all groups, with poor accuracy of detection (AUC ranging between 0.62 and 0.69 depending on migrant group).

In addition to comparing test performance of continuous anthropometric measures in detecting type 2 diabetes, we also examined test performance of 
Table 2 Age-adjusted prevalence of type two diabetes

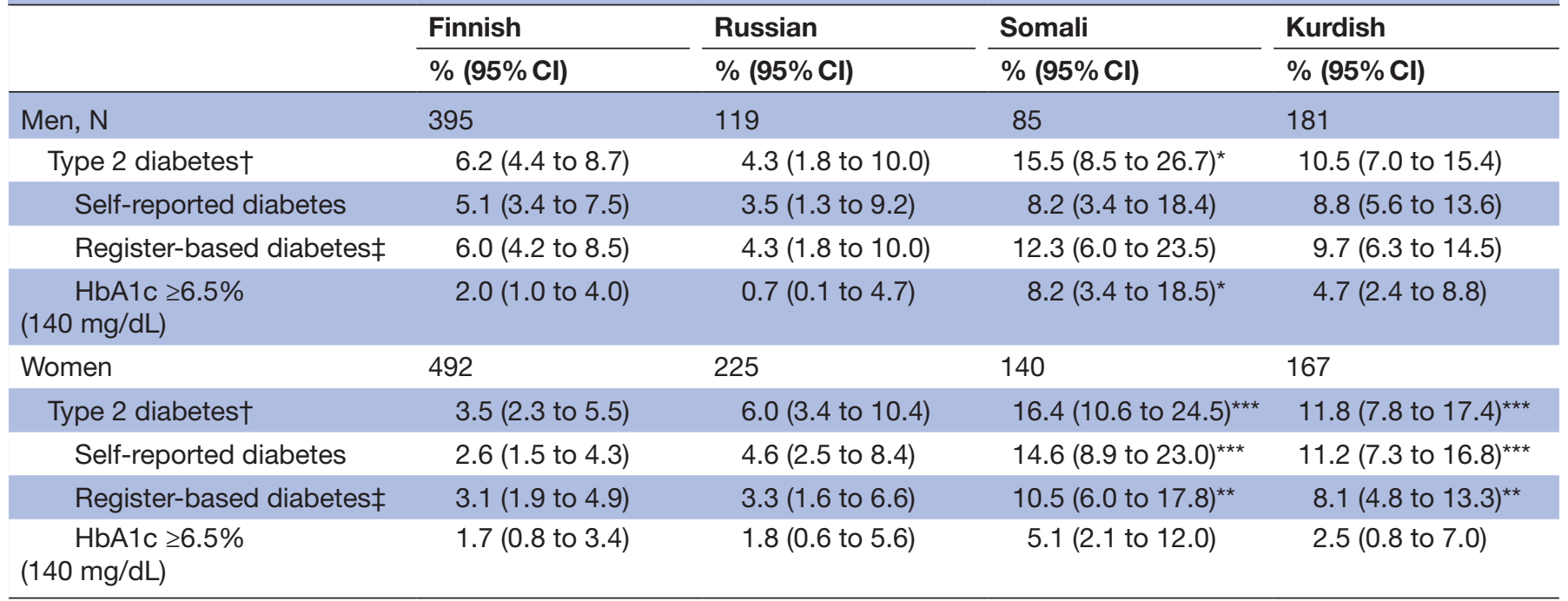

$P$ value is presented for the difference between each migrant group and Finns.

${ }^{*} \mathrm{P}<0.5,{ }^{* *} \mathrm{P}<0.001,{ }^{* *} \mathrm{P}<0.001$.

†Type 2 diabetes: self-reported diagnosis by a physician and/or self-reported diabetes medications and/or register-based diabetes and/or $\mathrm{HbA} 1 \mathrm{c} \geq 140 \mathrm{mg} / \mathrm{dL}$

†Register-based diabetes: register-based data on special medication reimbursement rights for diabetes medicine and/or inpatient or outpatient hospital care/physician visits for diabetes treatment.

HbA1c, glycated haemoglobin.

categorical anthropometric measures using established cut-off points for overweight and obesity (online supplementary table 1). These analyses showed a similar trend, however, accuracy of detection was slightly lower for categorical anthropometric measures compared with corresponding continuous anthropometric measures within each study group.

\section{DISCUSSION}

Our results suggest that out of the four examined anthropometric measures, WC and WHtR performed the best in detecting type 2 diabetes in all study groups. However, accuracy of prediction was better among Finns and Russians, compared with Somali and Kurds. There was some discordance in the prevalence of type 2 diabetes using different sources of information (self-report, registers and laboratory measures), highlighting the benefits of taking different data sources into account. Highest proportion of cases of screen-detected diabetes, that is, persons meeting the diabetes criteria of $\mathrm{HbAlc} \geq 6.5 \%$ $(140 \mathrm{mg} / \mathrm{dL}$ ) without previously known diabetes according to self-report or registers, was found among the Somali group $(2.2 \%)$, compared with $0.2 \%$ of Finns and $0.6 \%$ of Russians. This finding suggests the need for more effective screening for type 2 diabetes especially among Somali migrants.

Abdominal obesity is considered to be a central precursor for diabetes. ${ }^{8}$ Therefore, our finding that $\mathrm{WC}$ and WHtR are the best anthropometric measures for detecting type 2 diabetes is in line with previous research. Out of these two abdominal measures, WC is more established and is used in diabetes risk assessment tools. ${ }^{10}$ More recently, WHtR has been argued to be superior to a single measure of $\mathrm{WC}$ by taking into account intraindividual and ethnic differences in height. ${ }^{11} 13$ While we did find substantial differences in anthropometrics across study groups, our findings show very similar accuracy of detection for WC and WHtR within each study group. This may be related to an overall lower degree of the association between anthropometric measures with type 2 diabetes among non-Western origin migrants.

We also found an overall weaker association between anthropometrics and type 2 diabetes among Somali and Kurds. This was reflected through less pronounced differences in mean anthropometric values according to diabetes category as well as poorer accuracy of detection for WC and WHtR. In consistency with these findings, several previous studies report a lower level of correlation between obesity indicators and diabetes among non-Western origin migrants compared with Western populations. $^{2} 61428$

Higher prevalence of diabetes among South Asian origin migrants was not explained by obesity and other metabolic risk factors on follow-up. ${ }^{2}$ Middle Eastern origin migrants from Iraq had a significantly higher prevalence of both obesity and diabetes, however, high diabetes rates were only partly explained by abdominal obesity and other established risk factors for diabetes. ${ }^{28}$ Similarly, the association between body composition measures and diabetes was weaker among sub-Saharan African origin migrants compared with Western African origin migrants and persons in the Dutch general population. ${ }^{14}$ These differences may be attributable to genetic and epigenetic 


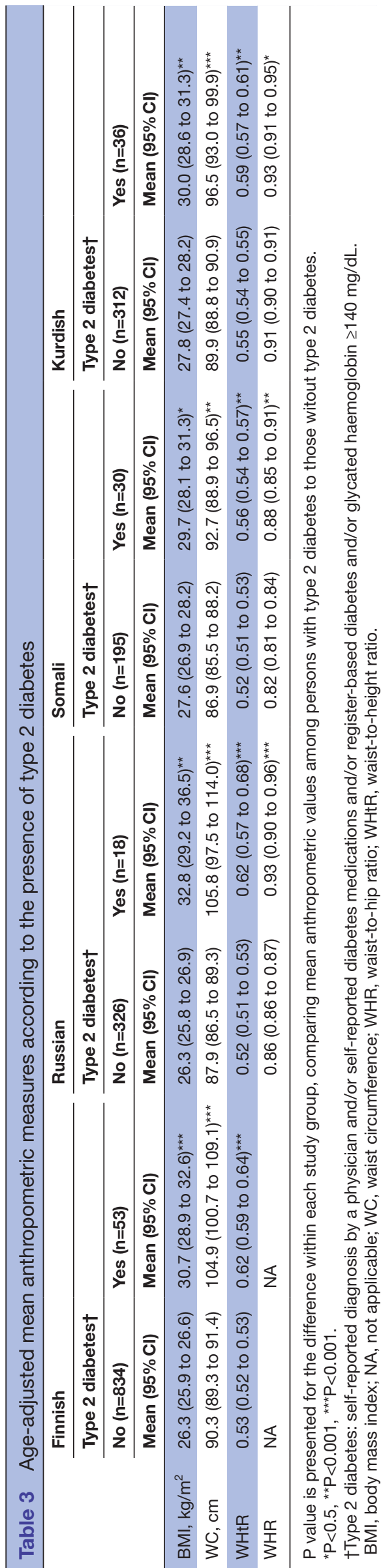

factors, ${ }^{1429}$ however, there is also emerging evidence that there may be different biological mechanisms behind glucose impairment according to country of origin. ${ }^{30-33}$

Glucose impairment among sub-Saharan Africans from Ghana appears to be more strongly related to peripheral insulin resistance than to beta cell dysfunction. ${ }^{32}$ Middle Eastern origin migrants (Lebanon, Iraq, Iran, Syria, Turkey) have been suggested to have an altogether different form of type 2 diabetes compared with Western populations due to a stronger genetic component, reflected in earlier age at onset, stronger family history and a more significant reduction in beta cell function despite similar insulin resistance levels. ${ }^{28}{ }^{31}$ Family history of diabetes has been found to have a stronger association with poorer glucose control than with age, BMI and WC among Iraqi origin migrants without diabetes. ${ }^{33}$

Non-Western origin migrants come from countries at an earlier stage of the epidemiological transition. Rapid epidemiological transition, with a notable change in diet and physical activity levels, may further contribute to a higher prevalence of glucose impairment and diabetes. ${ }^{32}{ }^{34}$ Rapid weight gain after migration may be related to glucose impairment among migrants. Furthermore, it has been suggested that a rapid transition from normal weight to overweight may be sufficient to produce glucose impairment and increase the likelihood of developing type 2 diabetes. ${ }^{30}$ 34-36

We used continuous anthropometric measures as opposed to conventional categorical measures because of an increasing amount of literature questioning the appropriateness of currently used obesity cut-offs validated among Caucasian populations in diabetes risk assessment among non-Western origin populations. ${ }^{15-17} 37$ Some studies have suggested that lower cut-offs for abdominal obesity among African men and higher cut-offs for African women may be more appropriate for detecting insulin resistance. ${ }^{15} 16$ Our findings support this as among persons with type 2 diabetes, Somali and Kurds had on average approximately $10 \mathrm{~cm}$ lower WC circumference compared with Finns and Russians. Lower cut-offs for BMI and WC may be more appropriate also for Middle Eastern origin migrants. Insulin resistance index of Middle Eastern origin (Iraqi) migrants at BMI $28.5 \mathrm{~kg} / \mathrm{m}^{2}$ for men and $27.5 \mathrm{~kg} / \mathrm{m}^{2}$ for women has been shown to correspond to that of Swedes with BMI $30 \mathrm{~kg} / \mathrm{m}^{2}$. Insulin sensitivity index among abdominally obese Swedes (WC $\geq 94 \mathrm{~cm}$ for men and $\geq 80 \mathrm{~cm}$ for women) corresponded to $10 \mathrm{~cm}$ lower cut-offs among Iraqi migrants $(\geq 84 \mathrm{~cm}$ for men and $\geq 71 \mathrm{~cm}$ for women). ${ }^{17}$

In addition to calculating ROC curves for continuous anthropometric measures, we tested the performance of categorical measures in detecting type 2 diabetes. Test performance was poorer for categorical compared with continuous anthropometric measures. Taking into account the increasing amount of evidence suggesting poorer applicability of categorical anthropometric measures in detecting diabetes 
Table 4 Receiver operating curve analysis area under the curve (AUC) for continuous anthropometric measures



BMI, body mass index; NA, not applicable; WC, waist circumference; WHR, waist-to-hip ratio; WHtR, waist-to-height ratio.

among non-Western origin populations, ${ }^{15-17} 37$ current use of categorical anthropometric measures in diabetes risk assessment may need to be reconsidered. Awareness of the limitations in the use of categorical anthropometric measures may facilitate development of more appropriate and sensitive tools for diabetes risk assessment among different population groups. Such have already been developed for cardiovascular risk prediction, which enable the use of continuous measures instead of the conventional cut-offs for cardiovascular risk factors. ${ }^{38} 39$ Additionally, the observed overall lower degree of the association between anthropometrics and diabetes among non-Western origin migrants may lead to a higher degree of misclassification of those at risk for developing diabetes. Therefore, diabetes risk assessment
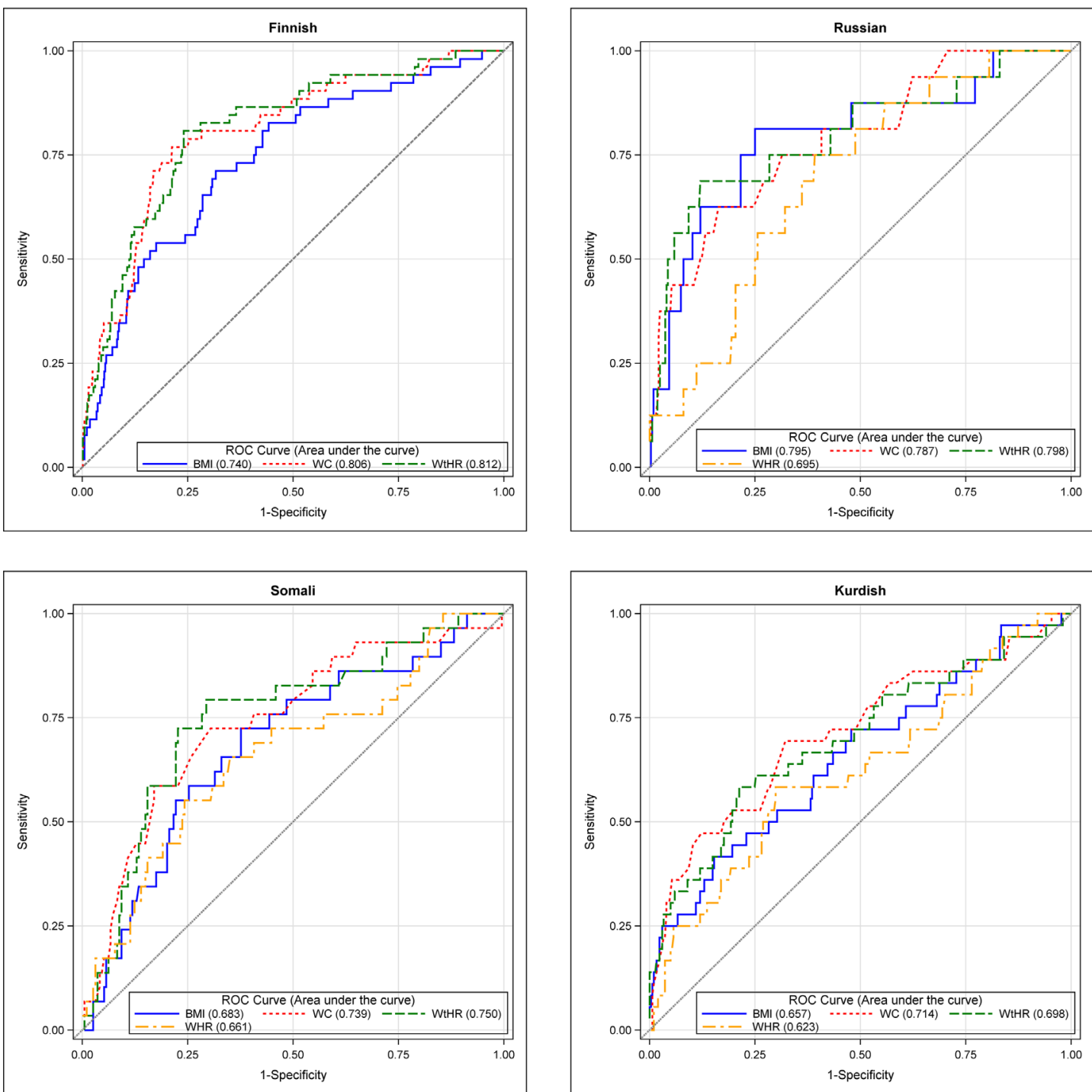

Figure 1 Age-adjusted receiver operating characteristics (ROC) curves for the association between anthropometrics and type 2 diabetes by study group. BMI, body mass index; WC, waist circumference; WHR, waist-to-hip ratio; WHtR, waist-to-height ratio. 
tools need to be validated among different population groups.

\section{Strengths and limitations}

A significant strength of this study is the use of several objective standardised anthropometric measures and supplementing self-reported data with register data and blood samples. An advantage of using HbAlc is that it measures average glucose levels over the past several weeks and is not affected by fasting. Use of anthropometric measures as continuous variables takes into account the lack of specific cut-offs for Middle Eastern and African origin populations. A further strength of this study is the randomised study design and inclusion of several migrant groups. Russian, Somali and Iranian/ Iraqi Kurds are significant migrant groups in Finland and in other Western countries. Kurds are a substantial refugee group in many European countries, USA and Canada but identification of Kurds in national statistics is particularly challenging as not all countries collect information on country of origin and mother tongue.

This study has also some limitations. Due to the cross-sectional nature of the data, we were unable to test causality by using follow-up data on diabetes diagnosis. Due to sample size restrictions, it was not feasible to calculate ROC curves for men and women separately. However, we did not observe interaction between sex and continuous anthropometric measures with respect to diabetes. Furthermore, type 2 diabetes risk assessment tools do not generally differentiate by sex and for this purpose as well, performing analyses jointly for men and women is plausible. Division of our study population according to country of origin has created relatively small study groups, resulting in widened CIs. Our findings need to be confirmed in a larger sample.

In conclusion, WC and WHtR were the best anthropometric measures for detecting type 2 diabetes among both Western and non-Western origin populations in our study. Out of the two, WHtR may be more appropriate for use in diabetes risk assessment as it takes into account intraindividual and ethnic differences in height and body composition. Currently used diabetes risk assessment tools have been designed for Western populations and assume that there is a high level of correlation between anthropometrics, and particularly abdominal obesity, with incidence of type 2 diabetes. Accuracy of anthropometric measures in detecting type 2 diabetes was lower among non-Western origin migrants. This may lead to a higher degree of misclassification of diabetes risk among non-Western origin populations. Non-Western origin migrants have a substantially higher prevalence of glucose impairment and diabetes than Finns, and effective screening strategies are needed for identification of those at high risk for developing diabetes.

Acknowledgements The authors would like to thank all the participants, fieldwork personnel and experts involved in the Maamu survey. We would like to thank Ville Peltokorpi for assisting with editing the figures.
Contributors NS analysed and interpreted the data and wrote the first draft of the manuscript. PK, TL and AL contributed to conceptualising the study design, data interpretation and provided critical review of the manuscript. TH and EL critically revised the statistical methods used in the study and contributed to data interpretation. All authors read and approved the final manuscript. All authors took responsibility for the integrity of the data and accuracy of the data analyses.

Funding This work was funded by the Doctoral Programme in Population Health, University of Helsinki, Finland.

Competing interests None declared.

Patient consent Not required.

Ethics approval Both surveys and record linkages were approved by the Coordinating Ethics Committee of the Helsinki and Uusimaa Hospital District.

Provenance and peer review Not commissioned; externally peer reviewed.

Data sharing statement The Migrant Health and Wellbeing (Maamu) Survey data can be shared with other researchers after a research plan has been compiled and accepted. More information on data sharing process can be accessed from: https:// www.thl.fi/en/web/thlfi-en/research-and-expertwork/population-studies/migranthealth-and-wellbeing-study-maamu-/information-for-researchers

Open Access This is an Open Access article distributed in accordance with the Creative Commons Attribution Non Commercial (CC BY-NC 4.0) license, which permits others to distribute, remix, adapt, build upon this work non-commercially, and license their derivative works on different terms, provided the original work is properly cited and the use is non-commercial. See: http://creativecommons.org/ licenses/by-nc/4.0/

(c) Article author(s) (or their employer(s) unless otherwise stated in the text of the article) 2018. All rights reserved. No commercial use is permitted unless otherwise expressly granted.

\section{REFERENCES}

1. Ujcic-Voortman JK, Baan CA, Seidell JC, et al. Obesity and cardiovascular disease risk among Turkish and Moroccan migrant groups in Europe: a systematic review. Obes Rev 2012;13:2-16.

2. Tillin T, Hughes AD, Wang Q, et al. Diabetes risk and amino acid profiles: cross-sectional and prospective analyses of ethnicity, amino acids and diabetes in a South Asian and European cohort from the SABRE (Southall And Brent REvisited) Study. Diabetologia 2015;58:968-79.

3. Bennet L, Groop L, Franks PW. Ethnic differences in the contribution of insulin action and secretion to type 2 diabetes in immigrants from the Middle East compared to native Swedes. Diabetes Res Clin Pract 2014;105:79-87.

4. Wändell PE, Johansson SE, Gåfvels C, et al. Estimation of diabetes prevalence among immigrants from the Middle East in Sweden by using three different data sources. Diabetes Metab 2008;34(4 Pt 1):328-33.

5. Choukem SP, Fabreguettes C, Akwo E, et al. Influence of migration on characteristics of type 2 diabetes in sub-Saharan Africans. Diabetes Metab 2014;40:56-60.

6. Meeks KA, Freitas-Da-Silva D, Adeyemo A, et al. Disparities in type 2 diabetes prevalence among ethnic minority groups resident in Europe: a systematic review and meta-analysis. Intern Emerg Med 2016;11:327-40.

7. Skogberg N, Laatikainen T, Koskinen S, et al. Cardiovascular risk factors among Russian, Somali and Kurdish migrants in comparison with the general Finnish population. Eur J Public Health 2016;26:667-73.

8. Eckel RH, Alberti KG, Grundy SM, et al. The metabolic syndrome. Lancet 2010;375:181-3.

9. Krentz AJ. Insulin resistance. BMJ 1996;313:1385-9.

10. Lindström J, Tuomilehto J. The diabetes risk score: a practical tool to predict type 2 diabetes risk. Diabetes Care 2003;26:725-31.

11. Ashwell M, Gunn P, Gibson S. Waist-to-height ratio is a better screening tool than waist circumference and BMI for adult cardiometabolic risk factors: systematic review and meta-analysis. Obes Rev 2012;13:275-86.

12. World Health Organization. Waist circumference and waist-to-hip ratio: report of a WHO expert consultation, Geneva, 8-11 December 2008: WHO Library Cataloguing-in-Publication Data, 2011. (ISBN 9789241501491).

13. Ashwell M, Gibson S. Waist-to-height ratio as an indicator of 'early health risk': simpler and more predictive than using a 'matrix' based on BMI and waist circumference. BMJ Open 2016;6:e010159. 
14. Meeks KA, Stronks K, Beune EJ, et al. Prevalence of type 2 diabetes and its association with measures of body composition among African residents in the Netherlands--The HELIUS study. Diabetes Res Clin Pract 2015;110:137-46.

15. Alberti KG, Eckel RH, Grundy SM, et al. Harmonizing the metabolic syndrome: a joint interim statement of the International Diabetes Federation Task Force on Epidemiology and Prevention; National Heart, Lung, and Blood Institute; American Heart Association; World Heart Federation; International Atherosclerosis Society; and International Association for the Study of Obesity. Circulation 2009;120:1640-5.

16. Sumner AE. The relationship of body fat to metabolic disease: influence of sex and ethnicity. Gend Med 2008;5:361-71.

17. Bennet L, Stenkula K, Cushman SW, et al. BMI and waist circumference cut-offs for corresponding levels of insulin sensitivity in a Middle Eastern immigrant versus a native Swedish population - the MEDIM population based study. BMC Public Health 2016;16:1242.

18. Lundqvist A, Mäki-Opas T. Health 2011 Survey - Methods. National Institute for Health and Welfare Report. 2016;8:31-2.

19. Social Institution of Finland. Statistics on reimbursements for prescription medicines. 2017. http://www.kela.fi/web/en/statisticsby-topic_statistics-on-reimbursements-for-prescription-medicines (accessed 23 Jun 2017.).

20. National Institute for Health and Welfare. Register descriptions. 2017 https://www.thl.fi/en/web/thlfi-en/statistics/information-on-statistics/ register-descriptions (accessed 23 Jun 2017).

21. Tolonen H, Koponen P, Mindell J, et al. European Health Examination Survey--towards a sustainable monitoring system. Eur J Public Health 2014;24:338-44.

22. Research Triangle Institute. SUDAAN Language Manual, Volumes 1 and 2, Release 11. Research Triangle Park, NC: Research Triangle Institute, 2012.

23. Robins JM, Rotnitzky A, Zhao LP. Estimation of Regression Coefficients When Some Regressors are not Always Observed. J Am Stat Assoc 1994;89:846-66.

24. Lehtinen RPE. Practical Methods for Design and Analysis of Complex Surveys. 2nd edn: John Wiley \& Sons, Ltd, 2004.

25. Graubard $\mathrm{BI}$, Korn EL. Predictive margins with survey data. Biometrics 1999;55:652-9.

26. Swets JA. Measuring the accuracy of diagnostic systems. Science 1988;240:1285-93.

27. DeLong ER, DeLong DM, Clarke-Pearson DL. Comparing the areas under two or more correlated receiver operating characteristic curves: a nonparametric approach. Biometrics 1988;44:837-45.
28. Bennet L, Nilsson PM. Country of birth modifies the associations of body mass and hemoglobin A1c with office blood pressure in Middle Eastern immigrants and native Swedes. $J$ Hypertens 2014;32:2362-70.

29. Agyemang C, Meeks K, Beune E, et al. Obesity and type 2 diabetes in sub-Saharan Africans - Is the burden in today's Africa similar to African migrants in Europe? The RODAM study. BMC Med 2016;14:166.

30. Hassoun S, Al-Atrash M, Alkasim M, et al. Impact of ethnicity and obesity on insulin resistance in two ethnic groups at very high risk of type 2 diabetes. Diabetes Metab 2017;43:292-4.

31. Glans F, Elgzyri T, Shaat N, et al. Immigrants from the Middle-East have a different form of Type 2 diabetes compared with Swedish patients. Diabet Med 2008;25:303-7.

32. Meeks KAC, Stronks K, Adeyemo A, et al. Peripheral insulin resistance rather than beta cell dysfunction accounts for geographical differences in impaired fasting blood glucose among sub-Saharan African individuals: findings from the RODAM study. Diabetologia 2017;60:854-64.

33. Bennet L, Lindblad U, Franks PW. A family history of diabetes determines poorer glycaemic control and younger age of diabetes onset in immigrants from the Middle East compared with native Swedes. Diabetes Metab 2015;41:45-54.

34. Vandenheede H, Deboosere P, Stirbu I, et al. Migrant mortality from diabetes mellitus across Europe: the importance of socio-economic change. Eur J Epidemiol 2012;27:109-17.

35. Ukegbu UJ, Castillo DC, Knight MG, et al. Metabolic syndrome does not detect metabolic risk in African men living in the U.S. Diabetes Care 2011;34:2297-9.

36. Morimoto Y, Schembre SM, Steinbrecher A, et al. Ethnic differences in weight gain and diabetes risk: the Multiethnic Cohort Study. Diabetes Metab 2011;37:230-6.

37. Skogberg N, Laatikainen T, Jula A, et al. Contribution of sociodemographic and lifestyle-related factors to the differences in metabolic syndrome among Russian, Somali and Kurdish migrants compared with Finns. Int J Cardiol 2017;232:63-9.

38. Goff DC, Lloyd-Jones DM, Bennett G, et al. 2013 ACC/AHA guideline on the assessment of cardiovascular risk: a report of the American College of Cardiology/American Heart Association Task Force on Practice Guidelines. Circulation 2014;129(Suppl 2):S49-73.

39. Vartiainen E, Laatikainen T, Peltonen M, et al. Predicting Coronary Heart Disease and Stroke: The FINRISK Calculator. Glob Heart 2016;11:213-6. 